----مجلة علوم الرافدين، المجلد 27، العدد 4/ عدد خاص بالمؤتمر العلمي الثالث لعلوم الحياة، ص243-257، 2018---

انتشار وتوزيع صفة المقاومة تجاه المضادات الحيوية والمعادن الثقيلة وامتلاك عوامل

الضراوة في بعض افراد البكتريا المعوية المعزولة من مصادر مختلفة

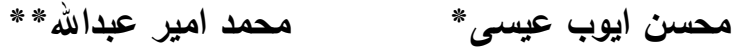

$$
\begin{aligned}
& \text { "قسم علوم الحياة / كلية العلوم / جامعة الموصل }
\end{aligned}
$$

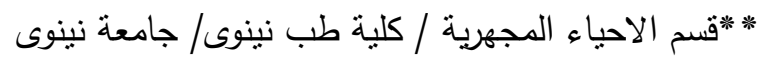

E-mail:drmuhsin68@yahoo.com

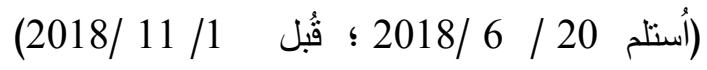

\title{
الملخص
}

اجري هذا البحث بهدف دراسة انتشار وتوزيع صفة المقاومة لبعض المضادات الحيوية واملاح المعادن الثقيلة وامتلاك عوامل

الضراوة في عزلات البكتريا المعوية Salmonella typhimurium و Escherichia coli المعزولة من مصادر مختلفة.

وأظهرت نتائج اختبارات الحساسية للمضادات الحيوية تباينا واضحا في توزيع وانتشار صفة المقاومة في العزلات الماخوذة من

مصدر واحد، او من مصادر متعددة لكل من بكتريا Salmonella typhimurium و Escherichia coli

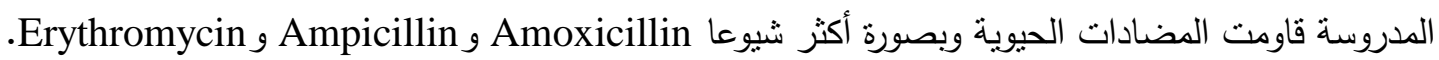

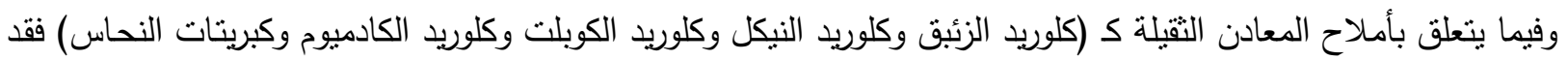

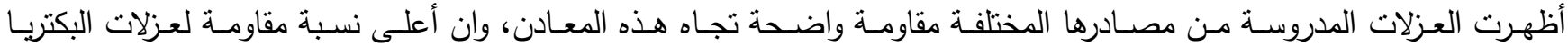

Escherichia coli وانتشار هذه الصفة باختلاف العزلة ومصدر العزل.

وتبين من خـلال النتائج الخاصـة بـالتحري عن امتلاك العزلات المدروسـة لبعض عوامل الضـراوة (الهيمولايسين، البروتيز ،

اليوريز ، الجيلاتتيز ) أن إنتـاج الهيمولايسـين كـان شـائعا في العديـ مـن عزلات نـوعي البكتريـا، كذلك البروتيز في بعض عض عزلات

Escherichia coli

لبقية عوامل الضراوة.

الكلمات الدالة: المضادات الحيوية المعادن الثقيلة، عوامل الضراوة، البكتريا المعوية.

\section{Spread and Distribution Antibiotics and Heavy Metals Resistance and Virulence Factors Possession in Some Members of Enterobacteria Isolated from Various Sources}

\author{
Muhsin A. Essa* \\ Mohammed A. Abdulah** \\ *Department of Biology /College of Science / University of Mosul \\ **Department of Microbiology /Nineveh College of Medicine /University of Nineveh
}




\section{ABSTRACT}

This study was conducted in an attempt to investigate the spread and the distribution of antibiotics and heavy metals resistance characteristic and virulence factors possession in some Enterobacteria Escherichia coli \& Salmonella typhimurium isolated from various sources.

The results of antibiotics sensitivity test showed a clear variation in the distribution and the spread of the resistance feature these antibiotics whether in the isolates from the same source or within different sources for both E. coli and S. typhimurium. Moreover, most of the isolates showed multiple resistance feature against the antibiotics and resistance against Amoxicillin, Ampicillin and Erythromycin was the most common amongst the studied isolates.

The heavy metals $\left(\mathrm{CuSO}_{4}, \mathrm{CoCl}_{2}, \mathrm{NiCl}_{2}, \mathrm{CdCl}_{2}\right.$ and $\left.\mathrm{HgCl}_{2}\right)$ sensitivity results showed a clear resistance against these metals salts and the highest percentage of the E. coli and the S. typhimurium was against $\mathrm{NiCl}_{2}$ which was $(93.3 \%)$ and $(73.3 \%)$ respectively. Also the distribution and the spread of this feature was variant based on the isolate and the source of the isolate.

From the results of investigating some virulence factors (Haemolysin, Protease, Urease and Gelatinase) results showed that the production of Haemolysin was common amongst many isolates of the two types of bacteria and the same was for the Protease in the Escherichia coli. The distribution of the virulence factors varied according to the isolates and the sources of these isolates, while results showed that the isolates do not have the other studied virulence factors.

Keywords: Antibiotics, Heavy metals, Virulence factors, Enterobacteria.

\section{المقدمة}

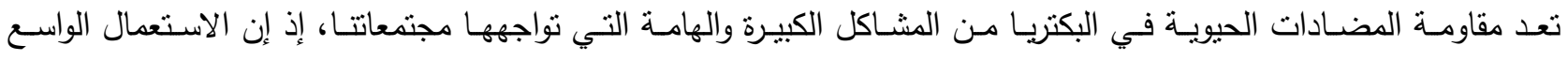

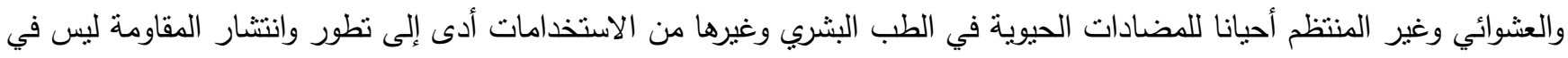
عزلات الإنسان والحيوان فحسب ولكن أيضـا في البيئة (Tollefson et al.,2008). إن مقاومة المضادات الحيوية خاصسة بين أفراد

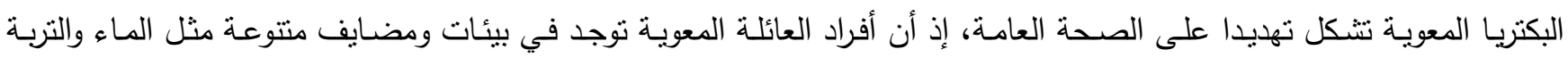
والنباتات والإنسان والحيوانات وتسبب إصابات خطيرة للإنسان (Andres et al., 2005). وقد تكون مقاومتها طبيعية أو مكتسبة، امـاء الطبيعية فتعتمد على الفسلجة والخواص الوراثية للبكتريا أو على التركيب الكيميائي للمضاد والية عمله، بينما المكتسبة فتعتمد على ولى الطفرات الوراثية التي قد تسبب ظهور جينات المقاومة وتتنقل عبر الأجيال والسلالات من نفس النوع أو بين أنواع مختلفة ضمن نفس لكس العائلة، أو عن طريق اكتساب جينات المقاومة من بكتريا إلى أخرى (Rachakonda and Cartee,2004)، بواسطة النقل الافقي

للجينات بواسطة البلازميدات التي تؤدي دورا مهماً في مقاومتها للمضادات الحيوية والمعادن التقبلة (Baquero et al.,2008).

واصبح التلوث بالمعادن الثقيلة إحدى اخطر المشاكل البيئية التي انتشرت بسبب التقدم الصناعي الناجم عن النشاط البشري ، ان التركيز العالي لهذه المعادن له تأثثر سلبي على النشاطات الوظيفية للمجتمعات البكتيرية في البيئة التي تتعرض لتراكيز عالية من

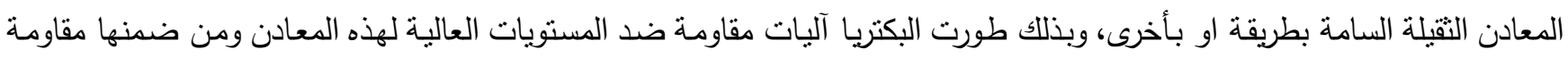
الضغط المعدني، وتحمل أيونات المعادن (Khan et al., 2009; Pandit et al., 2013) وهنالك علاقة مابين مقاومة المعادن النقيلة ومقاومة المضادات الحيوية اذ اظهرت دراسات عديدة بأن سلالات البكتريا المقاومة للمضادات الحيوية قد تظهر مقاومة للمعادن ايضا، ومما يؤدي الى تفاقم المشكلة وزيادة خطورتها هو امتلاكها لعوامل ضـراوة مثل انتاجها لأنزيمات كالهيمولايسين والبروتيز واليوريز والجيلاتتيز (Katzung,2004; Akinbowale et al., 2007). 
ونظراً لكون صفة المقاومة العلاجية وامتلاك عوامل الضراوة المختلفة هي من أهم مظاهر الخطورة لاى الجراثيم المعوية لذلك فإن إمكانية انتقال هذه الصفات من جرثومة إلى أخرى يعد مؤشرا خطيراً على تطور وانتشار العزلات البكتيرية المرضية الضارية والأمراض المرتبطة بها وانعكاس ذلك على الصحة العامة للمجتم، ولأجل تسليط الضوء على هذا الموضوع، لأهميته الصحية والبيئية فقد هدفت الدراسة الحالية إلى دراسة توزيع وانتشار صفة المقاومة للعلاجات والمعادن التقيلة وامتلاك عوامل الضراوة بين عزلات بعض البكاء البكتريا المعوية المعزولة من المصادر المختلفة.

\section{المواد وطرائق العمل}

1 العزلات البكتيرية

اسـتخدمت فـي هـه الدراسـة 15 عزلـة مـن كـل مـن بكتريـا Escherichia coli وبكتريـا السـالمونيلا بواقع خمس عزلات لكل منها معزولة من بيئة المستشفيات وخمس عزلات معزولة من مياه المجاري وخمس عزلات من عينات سريرية مرضية جميعها معزولة ومشخصة في قسم علوم الحياة /كلية العلوم / جامعة الموصل. الأوساط الزرعية

الاوساط الزرعية الواردة في هذه الدراسة أُعِدَّت وفقاً لما ورد في (Cruickshank,1975; MacFaddin,2000) او حسب

تعليمات الثركة المصنعة لها. أقراص المضادات الحيوية أُستُخدِمَت عشرة مضادات حيوية مجهزة من شركة Bioanalyse التركية مبينة مع نراكيزها في (الجدول 1).

الجدول 1: نوع وتركيز المضادات الحيوية المستخدمة في الاراسة

\begin{tabular}{|c|c|c|c|c|c|}
\hline 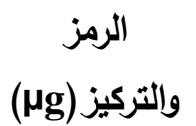 & المضاد الحيوي & ت & 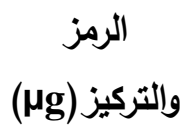 & المضاد الحيوي & $ت$ \\
\hline $\mathrm{E}_{30}$ & Erythromycin & 6 & $\mathrm{CN}_{10}$ & Gentamycin & 1 \\
\hline $\mathrm{TE}_{10}$ & Tetracyclin & 7 & $\mathrm{NA}_{30}$ & Nalidixic acid & 2 \\
\hline $\mathrm{AMP}_{25}$ & Ampicillin & 8 & $\mathrm{CIP}_{10}$ & Ciprofloxiacin & 3 \\
\hline $\mathrm{AK}_{30}$ & Amikacin & 9 & $\mathrm{AX}_{25}$ & Amoxicillin & 4 \\
\hline $\mathrm{CTX}_{10}$ & Cefotaxime & 10 & $\mathrm{TMP}_{25}$ & Trimethoprim & 5 \\
\hline
\end{tabular}

املاح المعادن الثقيلة

املاح المعادن النقيلة. من قسم الكيمياء/ كلية العلوم / جامعة الموصل.

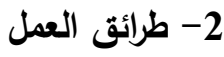

اختبار الحساسية للمضادات الحيوية 
أخضعت جميع العزلات البكتيرية لفصص الحساسية للمضادات الحيوية لدراسة تأثيرها في نمو البكتريا المعزولة وتم تحديد

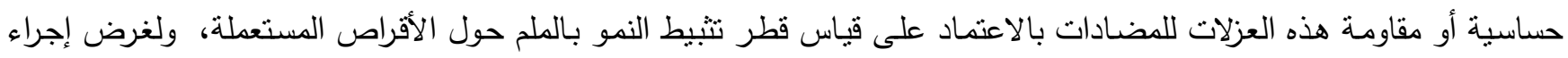

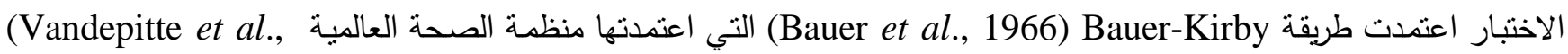

\section{اختبار الحساسية لاملاح المعادن الثقيلة}

تم تحضير أوساط املاح المعادن الثقيلة عن طريق اذابة هذه الاملاح في الماء المقطر المعقم للحصول على تركيز خزين

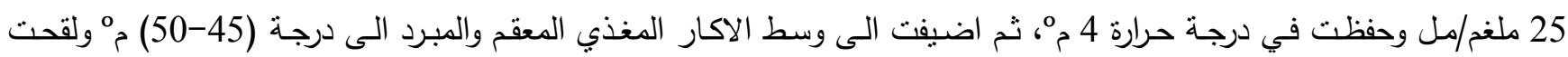

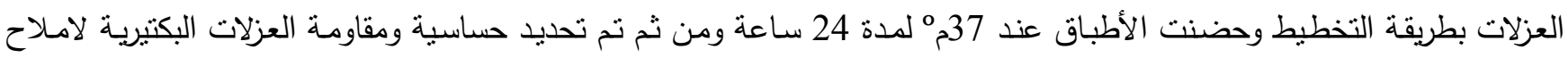

المعادن الثقيلة (Grant and Pittard,1974).

اختبارات الكثف عن عوامل الضراوة المدروسة

استتدت طرائق العمل في هذه الاختبارات الى (Cruickshank,1975; MacFaddin,2000) على النحو الآتي:

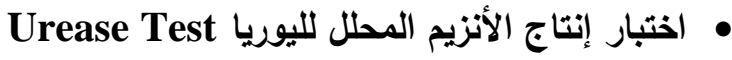

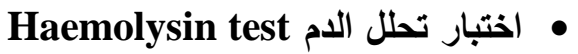

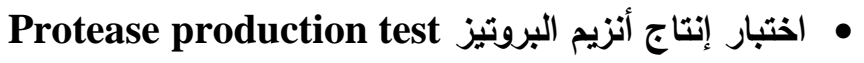

Gelatinase test اختبار إنتاج الأنزيم المميع للجيلاتين البروتز

\section{النتائج والمناقشتة \\ توزيع صفة المقاومة للمضادات الحيوية في عزلات البكتريا المعوية المدروسة :}

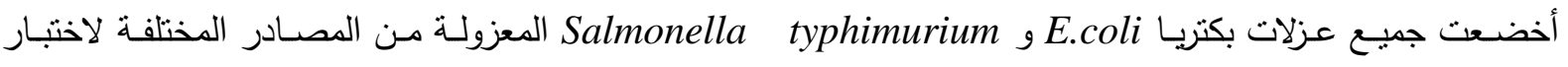
الحساسية للمضادات الحيوية لمعرفة صفة المقاومة بين العزلات ذات المصدر الواحد او ضمن المصادر المختلفة ـ ويوضح (الجدولان

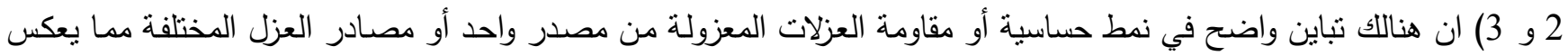

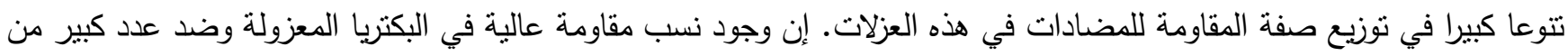

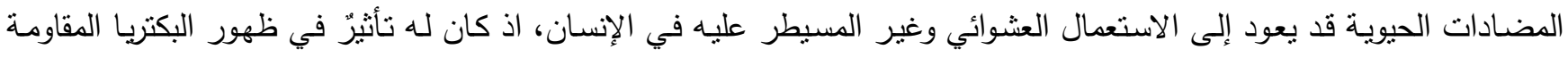

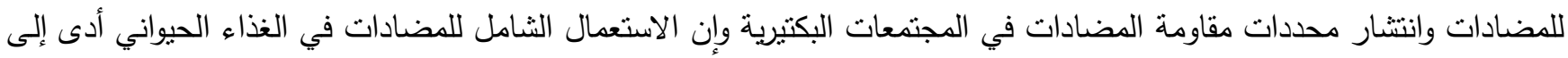

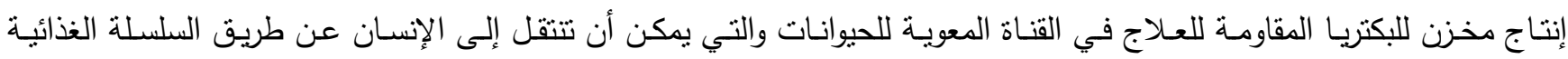

.(Cheong et al., 2014)

وبالنسبة لنمط الدقاومة المنفردة الذي يمثل مقاومة العزلات المختلفة للمضاد الواحد، يلاحظ في حالة عزلات بيئة المستشفى الماتي

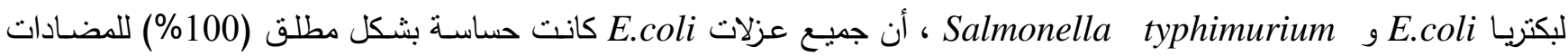

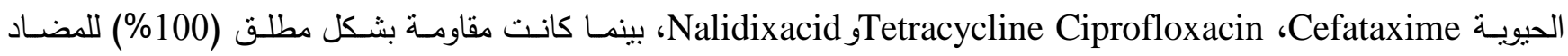

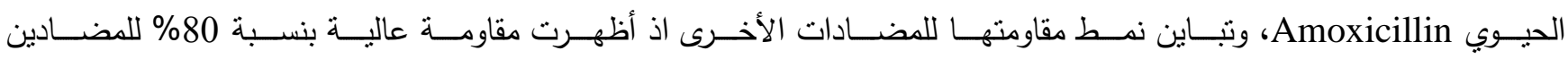

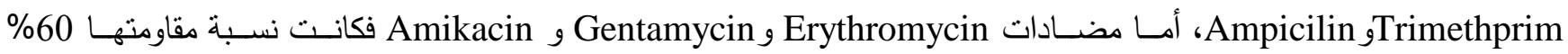
و 40\% و 20\% على النقالي. 
كذلك الحال بالنسبة لبكتريا Salmonella typhimurium لمعزولة من بيئة المستشفيات، اذ لوحظ مقاومتها العالية بنسبة

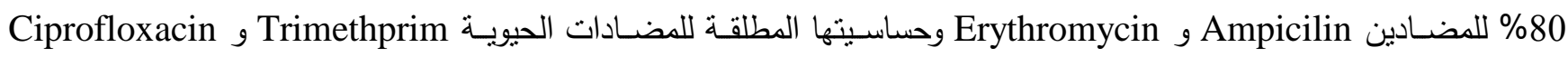
و Cefataxime Amikacin و أما مضادات Amoxicillin و و Tetracycline و Gentamycin و فكانت نسبة مقاومتها 20\%.

الجدول 2: نتائج فحوصات الحساسية لعزلات بكتريا E.coli تجاه المضادات الحيوية المدروسة.

Sensitive $=\mathbf{S}$

Resistance $=\mathbf{R}$

\begin{tabular}{|c|c|c|c|c|c|c|c|c|c|c|c|}
\hline \multicolumn{10}{|c|}{ المضادات الحيوية } & \multirow{2}{*}{ مصدر العزل } & \multirow[b]{2}{*}{$ت$} \\
\hline CTX & $\mathrm{AK}$ & NA & $\mathrm{CN}$ & AMP & CIP & Ery & TMP & AX & $\mathrm{TE}$ & & \\
\hline $\mathrm{S}$ & $\mathrm{S}$ & $\mathrm{S}$ & $\mathrm{S}$ & $\mathrm{R}$ & $\mathrm{S}$ & $\mathrm{S}$ & $\mathrm{R}$ & $\mathrm{R}$ & $\mathrm{S}$ & \multirow{5}{*}{ E: } & 1 \\
\hline $\mathrm{S}$ & $S$ & $\mathrm{~S}$ & $S$ & $\mathrm{R}$ & $S$ & $\mathrm{R}$ & $\mathrm{R}$ & $\mathrm{R}$ & $\mathrm{S}$ & & 2 \\
\hline$S$ & $\mathrm{R}$ & $S$ & $\mathrm{R}$ & $\mathrm{S}$ & $\mathrm{S}$ & $\mathrm{R}$ & $\mathrm{S}$ & $\mathrm{R}$ & $\mathrm{S}$ & & 3 \\
\hline $\mathrm{S}$ & $\mathrm{S}$ & $\mathrm{S}$ & $\mathrm{R}$ & $\mathrm{R}$ & $\mathrm{S}$ & $\mathrm{S}$ & $\mathrm{R}$ & $\mathrm{R}$ & $\mathrm{S}$ & & 4 \\
\hline $\mathrm{S}$ & $\mathrm{S}$ & $\mathrm{S}$ & $\mathrm{S}$ & $\mathrm{R}$ & $\mathrm{S}$ & $\mathrm{R}$ & $\mathrm{R}$ & $\mathrm{R}$ & $\mathrm{S}$ & & 5 \\
\hline$\% 0$ & $\% 20$ & $\% 0$ & $\% 40$ & $\% 80$ & $\% 0$ & $\% 60$ & $\% 80$ & $\% 100$ & $\% 0$ & \multicolumn{2}{|c|}{ \% اللمقاومة } \\
\hline $\mathrm{R}$ & $\mathrm{R}$ & $\mathrm{R}$ & $\mathrm{R}$ & $\mathrm{R}$ & $\mathrm{S}$ & $\mathrm{R}$ & $\mathrm{S}$ & $\mathrm{R}$ & $\mathrm{S}$ & \multirow{5}{*}{$\underline{E}$} & 6 \\
\hline $\mathrm{S}$ & $\mathrm{S}$ & $\mathrm{R}$ & $\mathrm{R}$ & $\mathrm{R}$ & $\mathrm{S}$ & $\mathrm{R}$ & $\mathrm{R}$ & $\mathrm{R}$ & $\mathrm{S}$ & & 7 \\
\hline $\mathrm{S}$ & $\mathrm{R}$ & $\mathrm{S}$ & $S$ & $\mathrm{R}$ & $\mathrm{S}$ & $\mathrm{R}$ & $\mathrm{R}$ & $\mathrm{R}$ & $\mathrm{S}$ & & 8 \\
\hline$S$ & $S$ & $\mathrm{R}$ & $\mathrm{S}$ & $\mathrm{R}$ & $\mathrm{S}$ & $\mathrm{R}$ & $\mathrm{S}$ & $\mathrm{R}$ & $\mathrm{S}$ & & 9 \\
\hline$S$ & $\mathrm{R}$ & $S$ & $\mathrm{~S}$ & $\mathrm{R}$ & $S$ & $\mathrm{R}$ & $S$ & $\mathrm{R}$ & $\mathrm{R}$ & & 10 \\
\hline$\% 20$ & $\% 60$ & $\% 60$ & $\% 40$ & $\% 100$ & $\% 0$ & $\% 100$ & $\% 40$ & $\% 100$ & $\% 20$ & \multicolumn{2}{|c|}{ \% اللمقاومة } \\
\hline $\mathrm{R}$ & $\mathrm{S}$ & $\mathrm{R}$ & $\mathrm{S}$ & $\mathrm{R}$ & $\mathrm{S}$ & $\mathrm{R}$ & $\mathrm{S}$ & $\mathrm{R}$ & $\mathrm{S}$ & \multirow{5}{*}{$\frac{E}{E}$} & 11 \\
\hline$S$ & $S$ & $\mathrm{R}$ & $\mathrm{S}$ & $\mathrm{R}$ & $S$ & $\mathrm{R}$ & $S$ & $\mathrm{R}$ & $\mathrm{R}$ & & 12 \\
\hline $\mathrm{R}$ & $\mathrm{R}$ & $S$ & $S$ & $\mathrm{R}$ & $S$ & $\mathrm{R}$ & $\mathrm{R}$ & $\mathrm{R}$ & $S$ & & 13 \\
\hline $\mathrm{S}$ & $\mathrm{R}$ & $\mathrm{S}$ & $\mathrm{S}$ & $\mathrm{R}$ & $\mathrm{S}$ & $\mathrm{R}$ & $\mathrm{S}$ & $\mathrm{R}$ & $\mathrm{S}$ & & 14 \\
\hline $\mathrm{S}$ & $\mathrm{S}$ & $\mathrm{S}$ & $\mathrm{R}$ & $\mathrm{R}$ & $\mathrm{S}$ & $\mathrm{R}$ & $\mathrm{R}$ & $\mathrm{S}$ & $\mathrm{R}$ & & 15 \\
\hline$\% 40$ & $\% 40$ & $\% 40$ & $\% 20$ & $\% 100$ & $\% 0$ & $\% 100$ & $\% 40$ & $\% 80$ & $\% 40$ & \multicolumn{2}{|c|}{ \% اللمقاومة } \\
\hline$\% 20$ & $\% 40$ & $\% .33$ & $\% .33$ & $\% .93$ & $\% 0$ & $\% .86$ & $\% .53$ & $\% .93$ & $\% 20$ & \multicolumn{2}{|c|}{ \% المنفردة الكلية } \\
\hline
\end{tabular}


إن النطابق في صفة المقاومة المنفردة المطلقة تجاه مضاد معين في عزلات المصدر الواحد وفي هذه الحالة بيئة المستشفى،

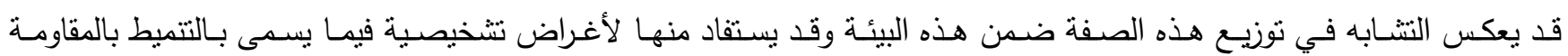
Resistotyping لغرض التحري عن السلالات المسببة للموجات الوبائية لبعض الأمراض والتحري عن مصادرها.

E.coli وتتـير الدراسـات إلـى انتشـار صـفة المقاومـة للمضـادات والعلاجـات بـين عـلات المستشـفيات ومنهـا بكتريـات

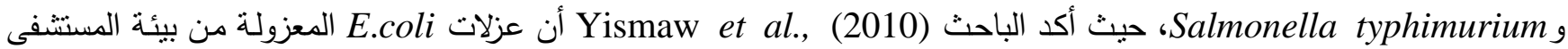
أظهـرت مقاومـة بنسـبة 47\% للمضــاد Gentamycin ونسـبة 33\% لمضــاد Ciprofloxacin وتتفـق نسـبة مقاومـة المضــاد Gentamycin

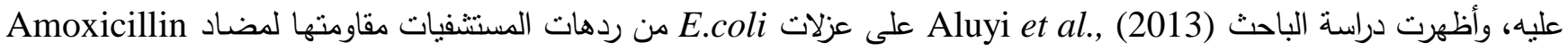
بنسبة 71.4 \% بنtracycline بنسبة 42.9\% ومضسبة مقاومة مضاد Nalidixacid كانت 32.1\% ، وأظهرت حساسية عالية

بنسبة 100\% لمضاد Ciprofloxacin. الجدول 3 : نتائج فحوصات الحساسية لعزلات بكتريا Salmonella typhimurium تجاه المضادات الحيوية المدروسة.

\begin{tabular}{|c|c|c|c|c|c|c|c|c|c|c|c|}
\hline \multicolumn{10}{|c|}{ المضادات الحيوية } & \multirow{2}{*}{ مصدر العزل } & \multirow[b]{2}{*}{$ت$} \\
\hline CTX & $\mathrm{AK}$ & NA & $\mathrm{CN}$ & Ery & CIP & AMP & TMP & $\mathrm{AX}$ & TE & & \\
\hline $\mathrm{S}$ & $\mathrm{S}$ & $\mathrm{S}$ & $\mathrm{S}$ & $\mathrm{R}$ & $\mathrm{S}$ & $\mathrm{R}$ & $\mathrm{S}$ & $\mathrm{S}$ & $\mathrm{S}$ & \multirow{5}{*}{ : } & 1 \\
\hline $\mathrm{S}$ & $\mathrm{S}$ & $\mathrm{R}$ & $\mathrm{S}$ & $\mathrm{R}$ & $\mathrm{S}$ & $\mathrm{S}$ & $\mathrm{S}$ & $\mathrm{R}$ & $\mathrm{S}$ & & 2 \\
\hline $\mathrm{S}$ & $\mathrm{S}$ & $\mathrm{S}$ & $\mathrm{S}$ & $\mathrm{S}$ & $S$ & $\mathrm{R}$ & $S$ & $\mathrm{~S}$ & $\mathrm{R}$ & & 3 \\
\hline $\mathrm{S}$ & $S$ & $\mathrm{~S}$ & $\mathrm{~S}$ & $\mathrm{R}$ & $S$ & $\mathrm{R}$ & $S$ & $\mathrm{~S}$ & $S$ & & 4 \\
\hline$S$ & $S$ & $S$ & $\mathrm{R}$ & $\mathrm{R}$ & $\mathrm{S}$ & $\mathrm{R}$ & $S$ & $S$ & $S$ & & 5 \\
\hline$\% 0$ & $\% 0$ & $\% 20$ & $\% 20$ & $\% 80$ & $\% 0$ & $\begin{array}{l}80 \\
\%\end{array}$ & $\% 0$ & $\% 20$ & $\% 20$ & \multicolumn{2}{|c|}{ \% للمقاومة المنفردة } \\
\hline$S$ & $\mathrm{~S}$ & $\mathrm{R}$ & $\mathrm{S}$ & $S$ & $\mathrm{~S}$ & $\mathrm{R}$ & $\mathrm{S}$ & $\mathrm{R}$ & $\mathrm{S}$ & \multirow{5}{*}{$\underline{E}$} & 6 \\
\hline $\mathrm{S}$ & $\mathrm{S}$ & $\mathrm{S}$ & $\mathrm{S}$ & $\mathrm{R}$ & $S$ & $\mathrm{~S}$ & $\mathrm{~S}$ & $\mathrm{~S}$ & $\mathrm{R}$ & & 7 \\
\hline $\mathrm{S}$ & $S$ & $\mathrm{~S}$ & $\mathrm{~S}$ & $\mathrm{R}$ & $\mathrm{S}$ & $\mathrm{R}$ & $\mathrm{S}$ & $\mathrm{R}$ & $\mathrm{S}$ & & 8 \\
\hline $\mathrm{S}$ & $S$ & $\mathrm{~S}$ & $\mathrm{~S}$ & $\mathrm{~S}$ & $\mathrm{~S}$ & $\mathrm{R}$ & $\mathrm{R}$ & $\mathrm{R}$ & $\mathrm{R}$ & & 9 \\
\hline $\mathrm{S}$ & $\mathrm{S}$ & $\mathrm{R}$ & $\mathrm{S}$ & $\mathrm{R}$ & $\mathrm{S}$ & $\mathrm{S}$ & $\mathrm{S}$ & $\mathrm{S}$ & $\mathrm{R}$ & & 10 \\
\hline$\% 0$ & $\% 0$ & $\% 40$ & $\% 0$ & $\% 60$ & $\% 0$ & $\% 60$ & $\% 20$ & $\% 60$ & $\% 60$ & \multicolumn{2}{|c|}{ \% للمقاومة المنفردة } \\
\hline $\mathrm{S}$ & $\mathrm{S}$ & $\mathrm{R}$ & $\mathrm{S}$ & $\mathrm{R}$ & $\mathrm{S}$ & $\mathrm{S}$ & $\mathrm{S}$ & $\mathrm{R}$ & $\mathrm{R}$ & \multirow{5}{*}{$\frac{\stackrel{G}{E}}{\frac{E}{E}}$} & 11 \\
\hline $\mathrm{S}$ & $S$ & $\mathrm{~S}$ & $\mathrm{R}$ & $\mathrm{S}$ & $\mathrm{S}$ & $\mathrm{R}$ & $\mathrm{R}$ & $\mathrm{R}$ & $\mathrm{S}$ & & 12 \\
\hline $\mathrm{S}$ & $S$ & $\mathrm{R}$ & $\mathrm{S}$ & $\mathrm{S}$ & $S$ & $\mathrm{~S}$ & $\mathrm{R}$ & $\mathrm{R}$ & $S$ & & 13 \\
\hline $\mathrm{S}$ & $S$ & $\mathrm{~S}$ & $\mathrm{R}$ & $\mathrm{R}$ & $\mathrm{S}$ & $\mathrm{R}$ & $S$ & $\mathrm{R}$ & $\mathrm{S}$ & & 14 \\
\hline $\mathrm{S}$ & $\mathrm{S}$ & $\mathrm{R}$ & $\mathrm{S}$ & $\mathrm{R}$ & $\mathrm{S}$ & $\mathrm{S}$ & $\mathrm{R}$ & $\mathrm{S}$ & $\mathrm{R}$ & & 15 \\
\hline$\% 0$ & $\% 0$ & $\% 60$ & $\% 40$ & $\% 60$ & $\% 0$ & $\% 40$ & $\% 60$ & $\% 80$ & $\% 40$ & \multicolumn{2}{|c|}{ \% لللمقاومة المنفردة } \\
\hline$\% 0$ & $\% 0$ & $\% 40$ & $\% 20$ & $\% 66.6$ & $\% 0$ & $\% 60$ & $\% 26.6$ & $\% 53.3$ & $\% 40$ & \multicolumn{2}{|c|}{ \% للمقاومة المنفردة الكلية } \\
\hline
\end{tabular}


وأوضتح الباحث (2013) Muhammed et al., في دراسته على عزل بكتريا Salmonella من بيئة المستشفيات إنها

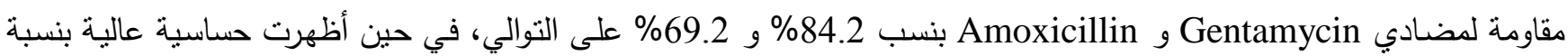
.Ciprofloxacin 100 100

بالعودة الى(الجدولين 2 و 3) يلاحظ أن نمط المقاومـة المنفردة لعزلات بيئة المستشفيات قد تباين مـع العزلات المرضية وعزلات مياه المجاري، فبالنسبة للمضـاد الحيوي Tetracycline نجد إن نسبة مقاومته كانت (20\%) في العزلات المرضبة لبكتريا

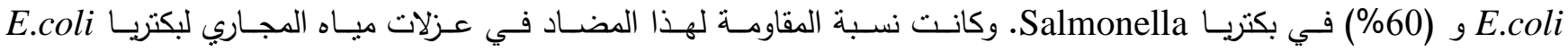
و Salmonella هي(40\%). كما نباينت نسبة المقاومة فيما يتعلق بالمضادات الأخرى. وهذا الأمر يعكس التباين في توزيع صفة ودة المقاومة لهذه المضادات باختلاف مصدر العزل. وان هذه الصفة منتشرة بشكل واسع في العزلات المرضية والبيئية لهاتين الجرثومتين.

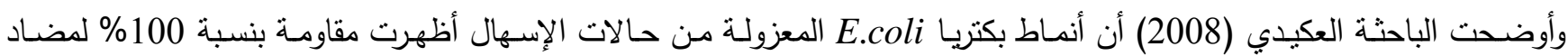

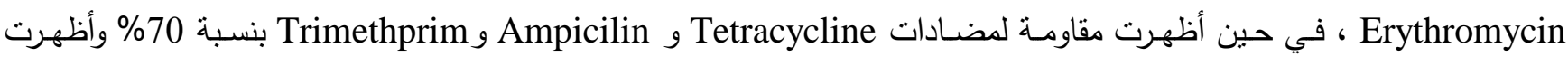

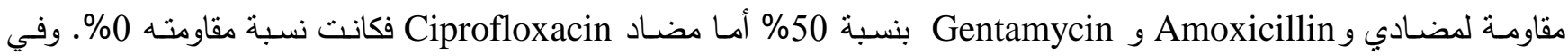
دراسـة في الأردن على أطفال مصابين بالإسهال أكد الباحث (2011) Alshara إن عزلات E.coli أظهرت مقاومة عالية لمضـاد

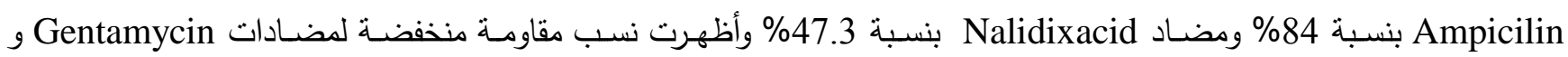
Cefataxime و Ciprofloxacin بينما بينت نتائج دراسة الباحثين (2013) Manikandan and Amsath على عزلات Salmonella من حالات إسهال امتلاكها مقاومسة عاليـة لمضـادي Amoxicillin و Ampicilin بنسبة 90.9\% وأظهرت مقاومسة منخفضـة بنسبة 18.2\% لمضـاد Nalidixacid بنسبة 100\%

وفيما يتعلق بمياه المجاري، أثنار الباحث (2012) Abo-state et al., إن عزلات E.coli من مياه المجاري أظهرت

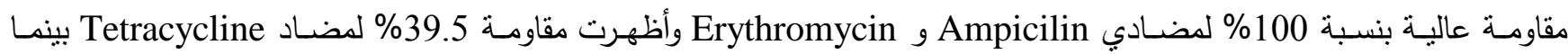

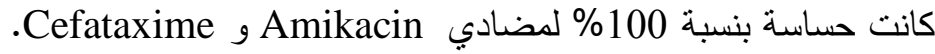
كما أكد الباحث (2012) Oubrim في دراسته على بكتريا Salmonella المعزولة من مياه المجاري مقاومتها لمضادي Tetracycline Ampicillin .Cefataxime g Amikacin g Ciprofloxacin Gentamycine وأظهرت نتائج دراسة الباحث Eze (2012) أن عزلات E.coli من مياه المجاري مقاومة 33.33 و 11.11\% لمضـاد Gentamycin وحساسـية عاليـة بنسبة 100\% لمضـادي Ciprofloxacin و Nalidixacid ، في حين أن عزلات Salmonella من مياه المجاري أظهرت مقاومـة 16\% لمضـاد Ampicilin و 8\% لمضـاد Ciprofloxacin وحساسية

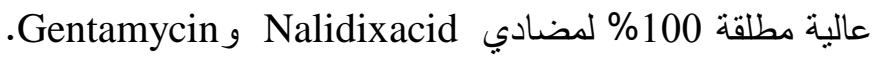
ويقترح التتويع الضخم لجينات مقاومة المضادات الحيوية في بكتريا امعاء الإنسان بأن البكتريا المقاومة للمضادات في هذه

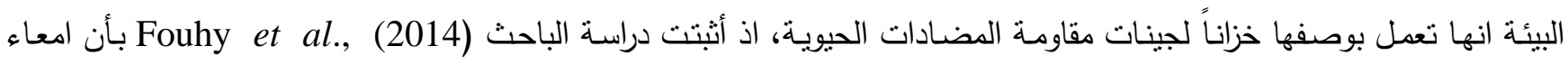
الإنسان يمكن أن تعد مصدرا لهذه الجينات اذ انها تتنقل مع البكتريا الممرضة الى البكتريا المتعايثـة في امعاء الانسان وتسبب مقاومة المضادات وفثنل العلاج مستقبلا (Licht and Wilcks, 2005). ووجود المضادات الحيوية في مياه المجاري يمكن أن تؤدي إلى لى لئ 


$$
\text { محسن ايوب عيسى و محمد امير عبداله }
$$

ظهور بكتريا مقاومـة للمضـادات الحيويـة من خـلال الضغط الانتخابي، حيث إن المضـادات الحيويـة لا تؤيض بشكل كامل في جسم الإنسان أو الحيوان الذي عولج بالمضـادات، إن 30\% و 90\% من الجرع التي تعطى للإنسان تطرح مـع البول والخروج كمواد فعالة

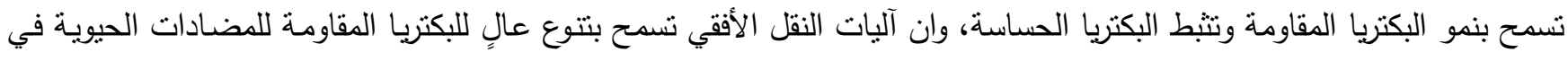

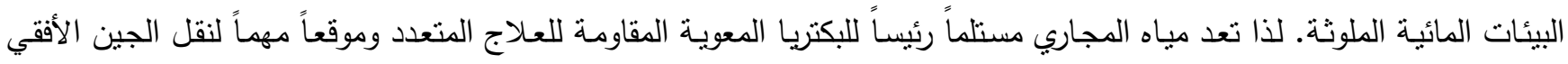

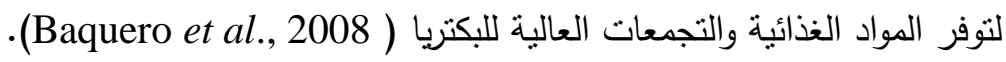
وبـالرجوع الى(الجدولين 2 و3) وملاحظـة نسبة المقاومـة المتعددة وانتشـارها بـين عزلات البكتريـا المدروسـة مسن المصـادر المختلفة يلاحظ إن جميع هذه العزلات امتلكت صفة المقاومة المتعددة للمضادات وان الاختلاف كان في عدد المضادات ونوعها، حيث

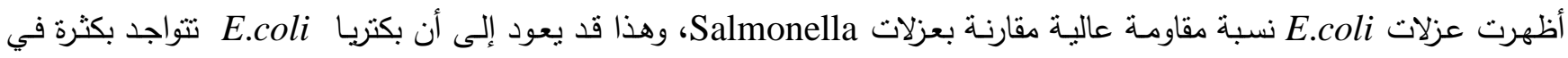

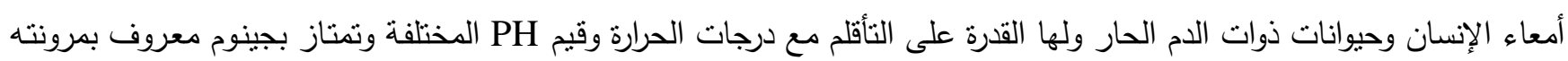

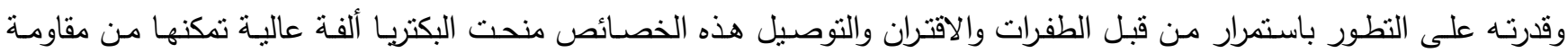
الظروف الصعبة والازدهار في بيئات مختلفة( Cruickshank et al.,1975). وأظهرت النتائج إن عزلات بكتريا E.coli المعزولة من حالات سريرية ومياه مجاري كانت نسبة مقاومتها المتعددة عالية حيث كانت 54\% و 50\% على التوالي، في حين كانت نسبة المقاومة المتعددة لعزلات E.coli المعزولة من بيئة المستشفيات 38

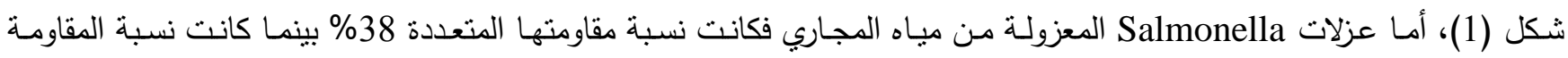
المتعدة لعزلاتها من حالات مرضية وبيئة المستشفيات 30\% و 24\% على على التوالي.

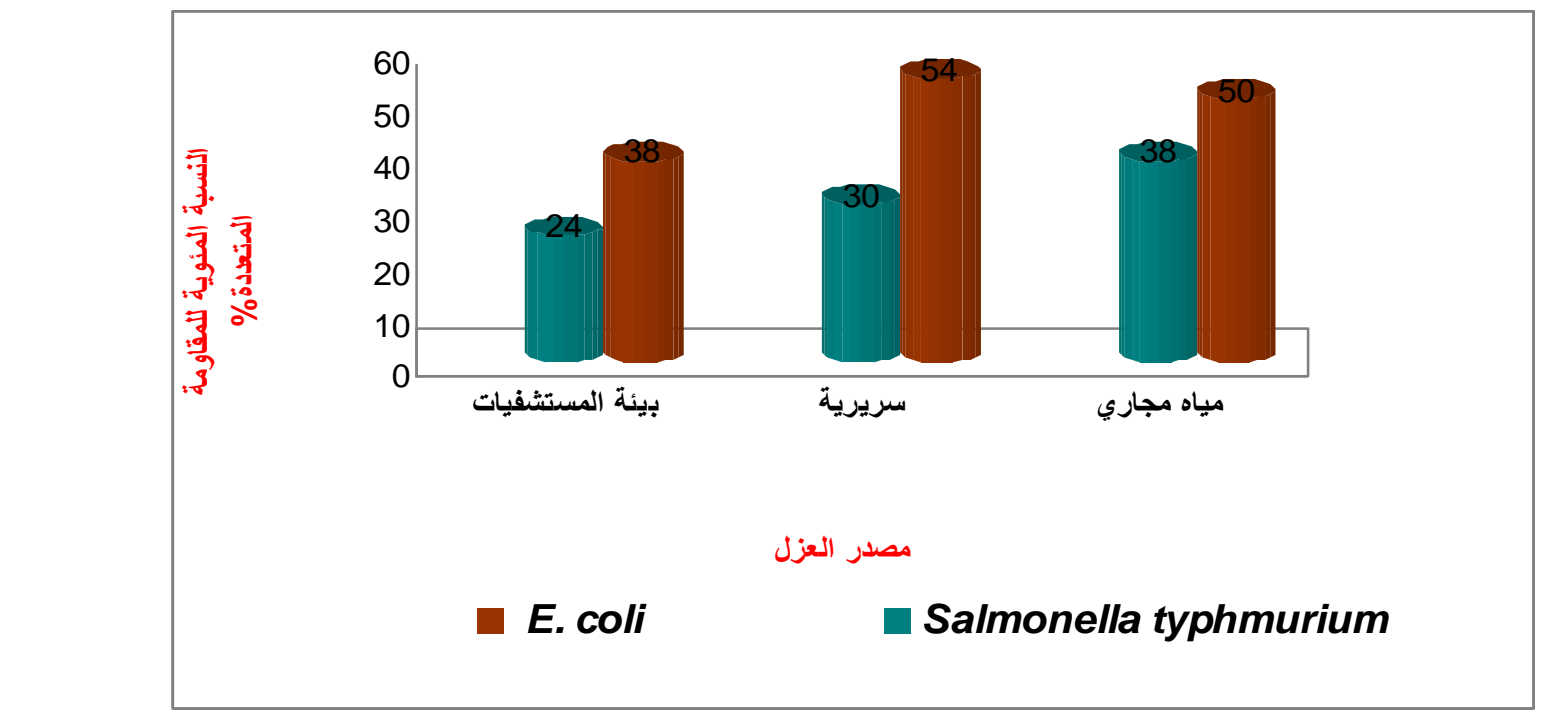

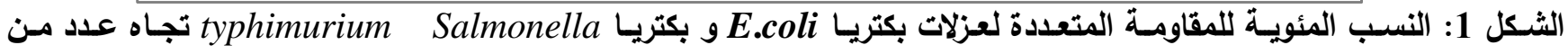
المضادات الحيوية المدروسة.

وان سبب المقاومة المتعددة قد تكون ناشئة من الطفرات التلقائية أو عن طريق انتقال بلازميدات أو جينات قافزة أو غيرها وتمتلك أهمية كبيرة في نشر المقاومة التي قد تتنقل من كروموسوم إلى بلازميد وهذا قد يفسر انتقال بعض الأنزيمات المسؤولة عن مقاومة المضادات إلى البلازميدات وبالتالي نشرها بين الأنواع البكتيرية عن طريق آليات نقل الجين الأفقي التي تشمل الاقتران البكتيري والتحول الوراثي والتوصيل(Selim and Hagag, 2013). 
توزيع صفة المقاومة لاملاح المعادن الثقيلة في عزلات البكتريا المعوية المدروسة:

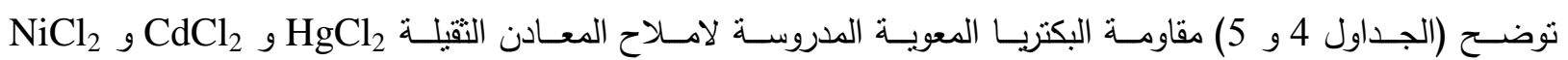

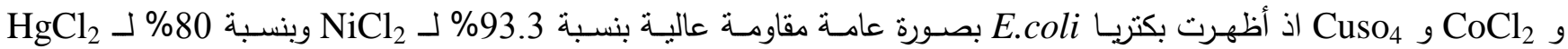

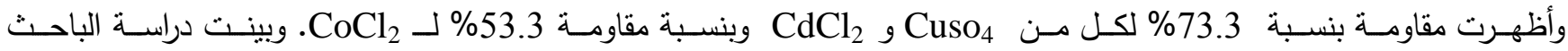
Karbasizaed et al., (2003) في دراستهز على بكتربـا E.coli المعزولـة من عدوى المستشفيات أن البكتربـا كانت مقاومـة

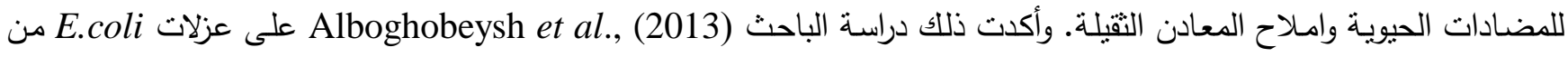
مياه المجاري حيث كانت مقاومة لاملاح المعادن Cu,Ni,Cd ومقاومة للمضادات الحيوية وهذا يماتل ما حصلنا عليه من نتائج.

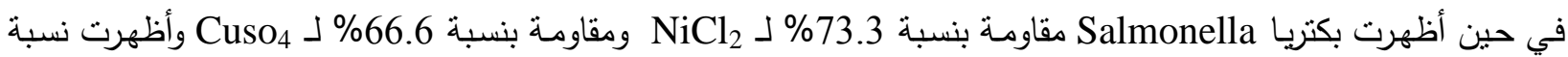
مقاومة 60\% لاملاح المعادن الثقيلة

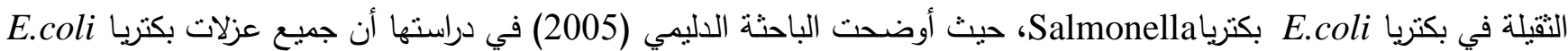

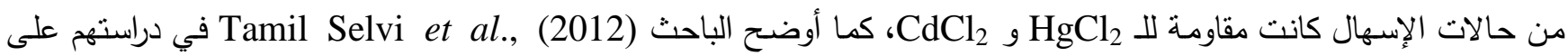

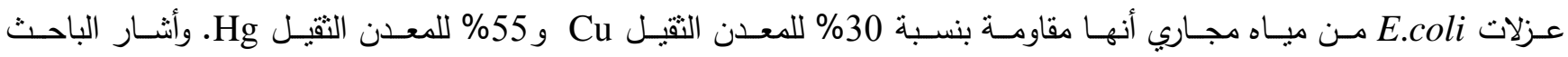
الى أن عزلات Sulayakul et al., (2011) المعزولة من مياه المجاري أظهرت مقاومة لكل من E.coli

الجدول 4: نتائج فحوصات الحساسية لعزلات بكتريا E.coli تجاه املاح المعادن الثقيلة المدروسة.

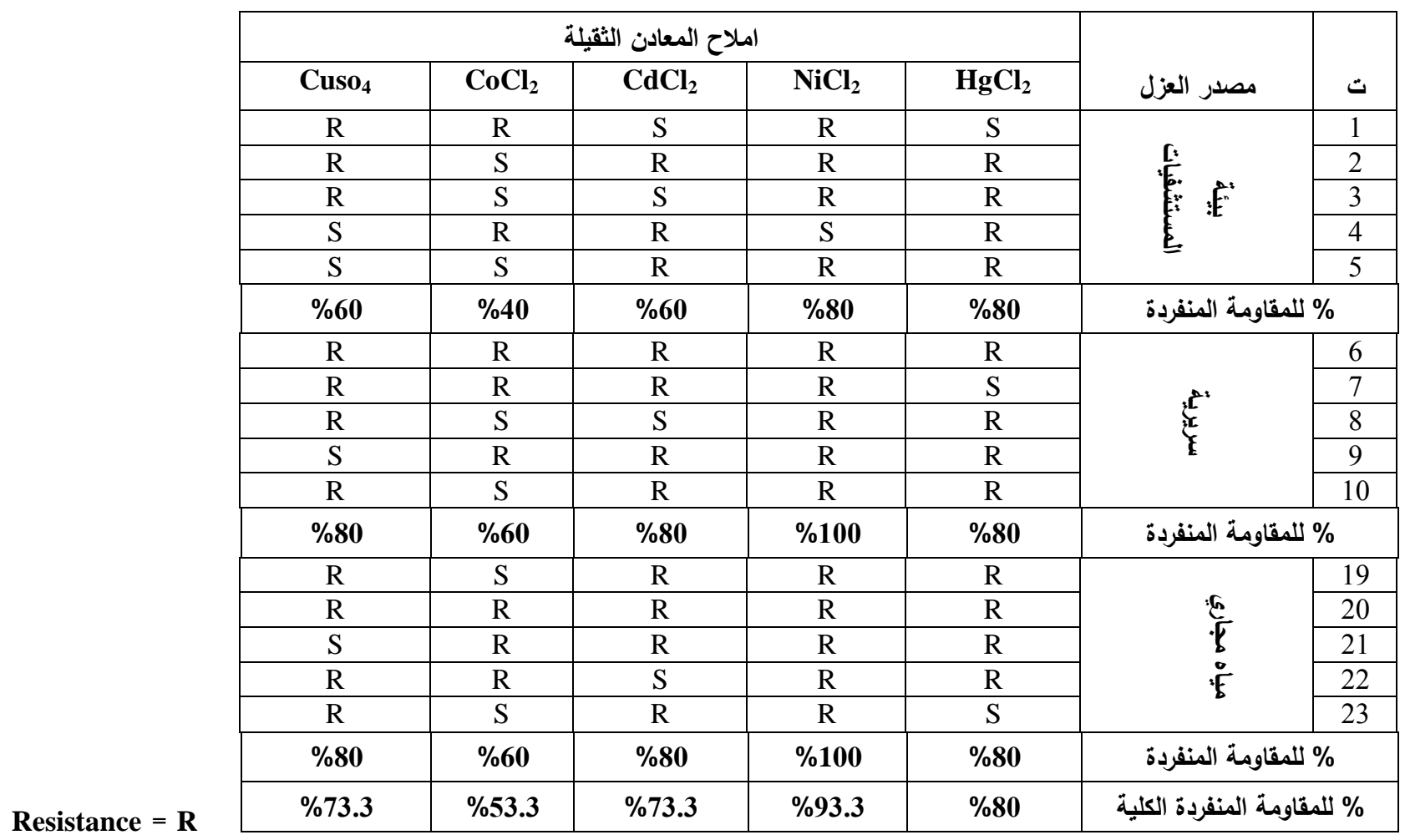

Sensitive $=\mathbf{S}$

(مقاومة) 
يلاحظ كذلك من النتائج تباين في توزيع صفة المقاومة لامـلاح المعادن الثقيلة ضمن عزلات المصدر الواحد للبكتريا نفسها وكذلك عزلات المصادر المختلفة كما تباينت نسب المقاومة لهذه الامهلاح بين عزلات نوعي البكتربا المعوية، ومن ثََّّ فإن هذه النتائج تعكس تتوعا واضحا في توزيع هذه الصفة ضمن العزلات المدروسة كما يتضح كذلك انتشار وشيوع هذه الصفة بنسبة مرتفعة في هذه

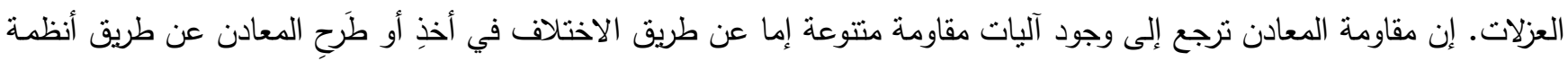

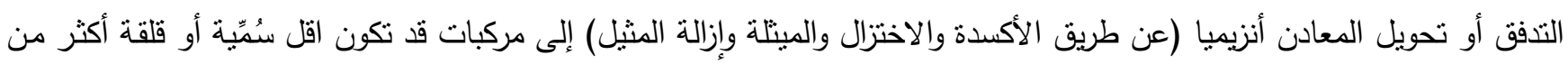
المركب الأصلي (Kamala-Kannan and Lee, 2008).

الجدول 5: نتائج فحوصات الحساسية لعزلات بكتريا Salmonella typhimurium تجاه املاح المعادن الثقيلة المدروسة.

\begin{tabular}{|c|c|c|c|c|c|c|}
\hline \multicolumn{5}{|c|}{ املاح المعادن الثقيلة } & \multirow[b]{2}{*}{ مصدر العزل } & \multirow[b]{2}{*}{$ت$} \\
\hline $\mathrm{CuSO}_{4}$ & $\mathrm{CoCl}_{2}$ & $\mathrm{CdCl}_{2}$ & $\mathrm{NiCl}_{2}$ & $\mathbf{H g C l}_{2}$ & & \\
\hline $\mathrm{R}$ & $\mathrm{S}$ & $\mathrm{R}$ & $\mathrm{S}$ & $\mathrm{S}$ & \multirow{5}{*}{ E: } & 1 \\
\hline $\mathrm{S}$ & $\mathrm{R}$ & $\mathrm{R}$ & $\mathrm{R}$ & $\mathrm{S}$ & & 2 \\
\hline $\mathrm{R}$ & $\mathrm{S}$ & $\mathrm{S}$ & $\mathrm{S}$ & $\mathrm{R}$ & & 3 \\
\hline $\mathrm{S}$ & $\mathrm{R}$ & $\mathrm{S}$ & $\mathrm{R}$ & $\mathrm{S}$ & & 4 \\
\hline $\mathrm{R}$ & $\mathrm{S}$ & $\mathrm{S}$ & $\mathrm{R}$ & $\mathrm{R}$ & & 5 \\
\hline$\% 60$ & $\% 40$ & $\% 40$ & $\% 60$ & $\% 40$ & \multicolumn{2}{|c|}{ \% للمقاومة المنفردة } \\
\hline $\mathrm{R}$ & $\mathrm{R}$ & $\mathrm{S}$ & $\mathrm{S}$ & $\mathrm{R}$ & \multirow{5}{*}{$\sum^{2 *}$} & 6 \\
\hline $\mathrm{R}$ & $\mathrm{S}$ & $\mathrm{R}$ & $\mathrm{R}$ & $\mathrm{R}$ & & 7 \\
\hline $\mathrm{S}$ & $\mathrm{R}$ & $\mathrm{R}$ & $\mathrm{R}$ & $\mathrm{S}$ & & 8 \\
\hline $\mathrm{R}$ & $\mathrm{R}$ & $\mathrm{R}$ & $\mathrm{R}$ & $\mathrm{S}$ & & 9 \\
\hline $\mathrm{R}$ & $\mathrm{R}$ & $\mathrm{R}$ & $\mathrm{R}$ & $\mathrm{R}$ & & 10 \\
\hline$\% 80$ & $\% 80$ & $\% 80$ & $\% 80$ & $\% 60$ & \multicolumn{2}{|c|}{ \% للمقاومة المنفردة } \\
\hline $\mathrm{R}$ & $\mathrm{R}$ & $\mathrm{R}$ & $\mathrm{R}$ & $\mathrm{S}$ & \multirow{5}{*}{$\begin{array}{l}\frac{5}{5} \\
\cdot \bar{b} \\
0 \\
\cdot 5\end{array}$} & 11 \\
\hline $\mathrm{S}$ & $\mathrm{S}$ & $\mathrm{R}$ & $\mathrm{R}$ & $\mathrm{R}$ & & 12 \\
\hline $\mathrm{R}$ & $\mathrm{R}$ & $\mathrm{S}$ & $\mathrm{S}$ & $\mathrm{R}$ & & 13 \\
\hline $\mathrm{R}$ & $\mathrm{S}$ & $\mathrm{S}$ & $\mathrm{R}$ & $\mathrm{R}$ & & 14 \\
\hline $\mathrm{S}$ & $\mathrm{R}$ & $\mathrm{R}$ & $\mathrm{R}$ & $\mathrm{R}$ & & 15 \\
\hline$\% 60$ & $\% 60$ & $\% 60$ & $\% 80$ & $\% 80$ & \multicolumn{2}{|c|}{ \% للمقاومة المنفردة } \\
\hline$\% 66.6$ & $\% 60$ & $\% 60$ & $\% 73.3$ & $\% 60$ & \multicolumn{2}{|c|}{ \% للمقاومة المنفردة } \\
\hline
\end{tabular}


كما بينّت النتائج ان البكتريا المتحملة لملح المعدن النقيل النيكل كانت لها مقاومة عالية تجاه المضاد الحيوي Ampicillin، وهذه النتائج اتفقت مـع نتائج الباحثة (2012) Christina et al., التي اظهرت بان التحمل المضاعف للمضـاد - المعدن حصل بين المضاد Ampicillin والنيكل.

إن قدرة البكتريا على مقاومـة المضـادات الحيويـة والمعادن الثقيلة يمكن أن تسبب تعقيدات صحية خطيرة بسبب قدرة هذه الأحياء المجهرية على نقل جينات المقاومة بوساطة R-plasmid إلى البكتريا الأخرى والتي سوف تؤثر في المجتمع البكتيري وبذلك تسبب تعقبد المعالجة (Mgbemena et al., 2012)

\section{توزيع عوامل الضراوة المدروسة في عزلات البكتريا المعوية المعزولة من مصادر مختلفة:}

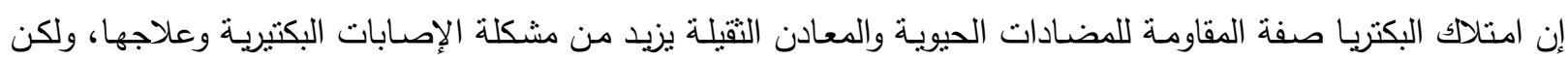
امتلاك البكتريا للعديد من عوامل الضراوة المنمنلة بإنتاج الأنزيمات كالهيمولايسين والبروتيز واليوريز والجيلاتتيز وغيرها من عوامل الضراوة يزيد من خطورة هذه المشكلة وتعقيدها (Katzung, 2004).

وبينت النتائج الموضحة في (الجدولين 6 و 7) إن 6 عزلات من بكتريا E.coli كانت منتجة للهيمولايسين بنسبة 40\%، وندان أما

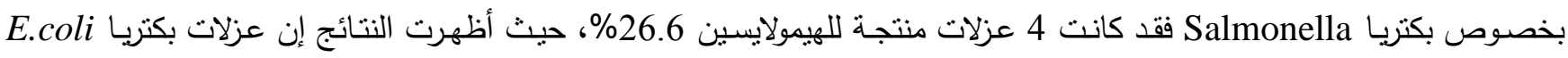
وبكتريا Salmonella المعزولة من حالات إسـهال أظهرت أعلى نسبة إنتاج لأنزيم الهيمولايسين حيث كانت 60\% و 40\% التوالي.

وأظهرت النتائج أن خمس عزلات من بكتريا E.coli منتجة لأنزيم البرونيز 33.3\% ، وان عزلات بكتريا E.coli المعزولة

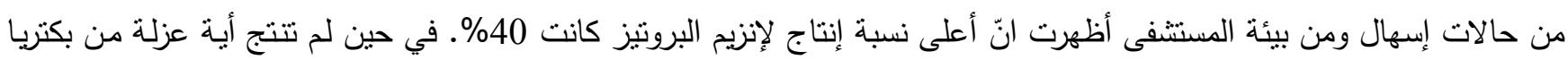

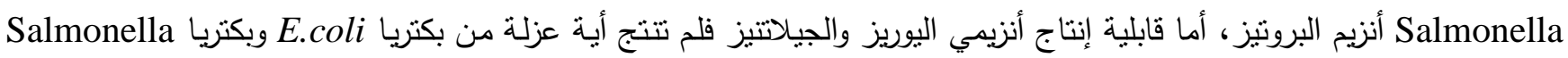

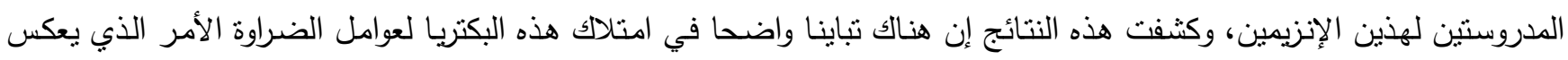
تتوعا أيضا في توزيع هذه الصفة سواء ضدن عزلات المصدر الواحد أو المصادر المختلفة للعزل.

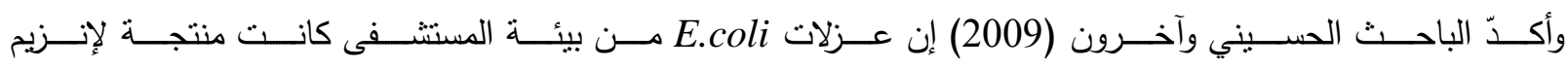
الهيمولايسين بنسبة 60.5\% وأنزيم البروتيز بنسبة 72\% ، في حين لـم تتنج أيسة عزلـة أنزيم اليوريز ، كما أظهرت نتائج الباحث Abskharon et al., (2009) من مياه المجاري لم تتتج أنزيمي اليوريز والجيلاتتيز وهذا يماثل ما حصلنا عليه من نتائج، فيما أنثار (Sharma et al., (2007 الى أن 4 عزلات E.coli من مجموع 152 أظهرت نتيجة موجبة لإنزيم الجيلانتيز وهذا يختلف عن نتائجنا، في حين أشارت دراسة الباحث (2011),.Doughari et al. الى أن 60\% من عزلات E.coli المعزولة من

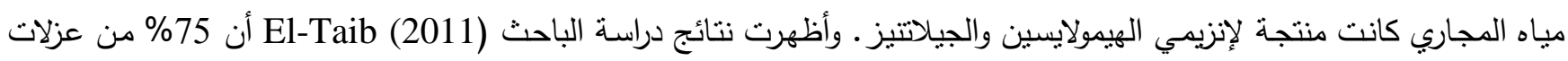
Salmonella 
محسن ايوب عيسى و محمد امبر عبداله

الجدول 6: نتائج اختبارات الكثف عن بعض عوامل الضراوة المدروسة في عزلات بكتريا E.coli.

\begin{tabular}{|c|c|c|c|c|c|}
\hline \multicolumn{4}{|c|}{ عوامل الضراوة } & \multirow[b]{2}{*}{ مصدر العزل } & \multirow[t]{2}{*}{$ت$} \\
\hline اليوريز & الجيلاتتيز & البروتيز & الهيمولايسين & & \\
\hline- & - & - & - & \multirow{5}{*}{ 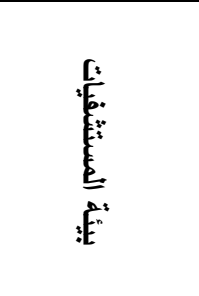 } & 1 \\
\hline- & - & + & + & & 2 \\
\hline- & - & - & - & & 3 \\
\hline- & - & - & - & & 4 \\
\hline- & - & + & - & & 5 \\
\hline$\% 0$ & $\% 0$ & $\% 40$ & $\% 20$ & \multicolumn{2}{|c|}{ \% لوجود عامل ضراوة واحد } \\
\hline- & - & + & + & \multirow{5}{*}{ 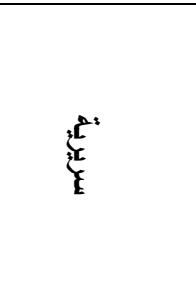 } & 6 \\
\hline- & - & + & - & & 7 \\
\hline- & - & - & + & & 8 \\
\hline- & - & - & - & & 9 \\
\hline- & - & - & + & & 10 \\
\hline$\% 0$ & $\% 0$ & $\% 40$ & $\% 60$ & \multicolumn{2}{|c|}{ \% لوجود عامل ضراوة واحد } \\
\hline- & - & - & + & \multirow{5}{*}{$\frac{E}{E}$} & 11 \\
\hline- & - & - & - & & 12 \\
\hline- & - & - & + & & 13 \\
\hline- & - & - & - & & 14 \\
\hline- & - & + & - & & 15 \\
\hline$\% 0$ & $\% 0$ & $\% 20$ & $\% 40$ & \multicolumn{2}{|c|}{ \% لوجود عامل ضراوة واحد } \\
\hline$\% 0$ & $\% 0$ & $\% 33.3$ & $\% 40$ & \multicolumn{2}{|c|}{ \% الكلية لوجود عامل ضراوة } \\
\hline
\end{tabular}

+

نستتنج من خلال دراستتا الحالية بغض النظر عن مصدر العزلة أنّ السلالات البكتيرية قد يكون خطرها بدرجة واحدة، اذ إن

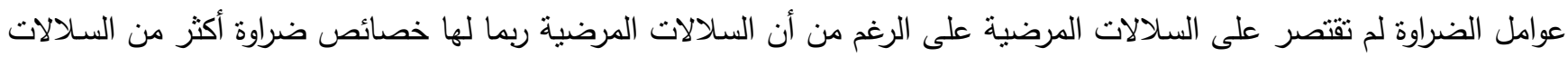
البكتيرية من المصادر الأخرى التي يمكن أن تكون ضـارية عند نوفر الظروف المناسبة وتشكل خطرا على الصحة العامة. إن أكثر عزلات بيئة المستشفيات وبيئة مياه المجاري لا تختلف كثيرا بوجود عوامل الضراوة ومقاومة المضـادات الحيوية والمعادن الثقيلة عن السـلالات المرضية، وبالتالي فأن الانتشـار البيئي لهذه البكتريا المرضية يشكل تهديدا وخطرا على صحة الإنسان ويبدو أن مقاومـة المضادات الحيوية والمعادن الثقيلة وعوامل الضراوة تكون شائعة في البكتريا المعويـة بغض النظر عن مصادر عزلها، ويُسهه الإنسان في انتخاب الأحياء المجرية المقاومة والضارية عن طريق سوء استعمال المضادات الحيوية ليس في المسنتفيات فحسب ولكن أيضا بـان في الزراعة والطب البيطري وإطلاق النفايات الصناعية الحاوية على المضـادات الحيوية والمعادن النقيلة إلى البيئة، وتعد هذه البيئات 
خزاناً جيداً للبكتريا المقاومة والضـارية وجينات المقاومة التي تكون في مثل هذه البيئات قادرة على اكتساب وتبادل المحددات الوراثية المسؤولة عن مقاومة متعددة للعلاج وتحمل المعادن التقبلة وعوامل الضراوة وتتقل إلى المستشفيات وبالعكس.

الجدول7: نتائج اختبارات الكثف عن بعض عوامل الضراوة المدروسة في عزلات بكتريا Salmonella typhimurium .

\begin{tabular}{|c|c|c|c|c|c|}
\hline \multicolumn{4}{|c|}{ عوامل الضراوة } & \multirow[b]{2}{*}{ مصدر العزل } & \multirow[t]{2}{*}{$ت$} \\
\hline اليوريز & الجيلاتتيز & البروتيز & الهيمولايسين & & \\
\hline- & - & - & - & \multirow{5}{*}{ 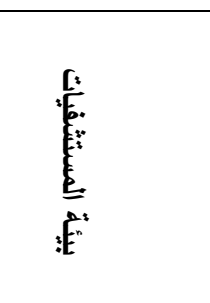 } & 1 \\
\hline- & - & - & + & & 2 \\
\hline- & - & - & - & & 3 \\
\hline- & - & - & - & & 4 \\
\hline- & - & - & - & & 5 \\
\hline$\% 0$ & $\% 0$ & $\% 0$ & $\% 20$ & \multicolumn{2}{|c|}{ \% لوجود عامل ضراوة واحد } \\
\hline- & - & - & + & \multirow{5}{*}{ है } & 6 \\
\hline- & - & - & - & & 7 \\
\hline- & - & - & - & & 8 \\
\hline- & - & - & + & & 9 \\
\hline- & - & - & - & & 10 \\
\hline$\% 0$ & $\% 0$ & $\% 0$ & $\% 40$ & \multicolumn{2}{|c|}{ \% لوجود عامل ضراوة واحد } \\
\hline- & - & - & - & \multirow{5}{*}{$\frac{\sqrt[n]{E}}{\frac{E}{E}}$} & 11 \\
\hline- & - & - & - & & 12 \\
\hline- & - & - & + & & 13 \\
\hline- & - & - & - & & 14 \\
\hline- & - & - & - & & 15 \\
\hline$\% 0$ & $\% 0$ & $\% 0$ & $\% 20$ & \multicolumn{2}{|c|}{ \% لوجود عامل ضراوة واحد } \\
\hline$\% 0$ & $\% 0$ & $\% 0$ & $\% 26.6$ & \multicolumn{2}{|c|}{ \% الكلية لوجود عامل ضراوة واحد } \\
\hline
\end{tabular}

المصادر العربية

الحسيني، رعد خليل؛ عبداللطيف، رغد ؛ الجوفي، اقبال خضر (2009). دراسة إنتاجية بعض عوامل الضراوة لبعض البكتريا المعزولة

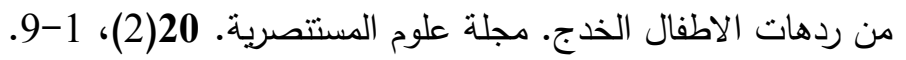

الدليمي، آلاء سعيد شيت (2005). تحييد محتوى الـ DNA البلازميدي في جرثومة Escherichia coli المعزولة من حالات إسهال الأطفال باستخدام الاكردينات والريفامبين وتأثير السكريات في نمو الجرثومة. رسالة ماجستير ، كلية العلوم، جامعة الموصل.

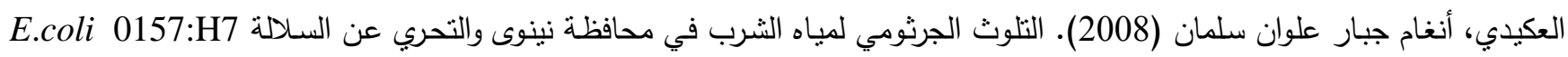
وعلاقتها بمجالات إسهال الأطفال دون سن الخامسة. رسالة ماجستير ، كلية العلوم، جامعة الموصل. 


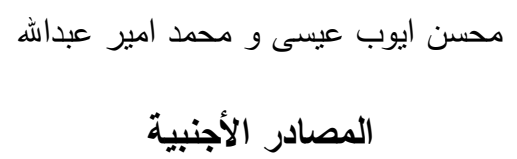

Abo-State, M.A.; Mahdy, H.M.; Ezzat, S.M.; Abd El Shakour, E.H.; El-Bahnasawy, M.A.(2012). Antimicrobial resistance profiles of enterobacteriaceae isolated from rosetta branch of river nile, egypt. World J.Appl.Sci.,19(9),1234-1243.

Abskharon, R.N.N.; Gad El-Rab, S.M.F.; Hassan, S.H.A.; Shoreit, A.A.M.(2009). Reduction of toxic hexavalent chromium by E. coli. Global J.Biotech. Biochem., 4(2), 98-103.

Akinbowale, O.L.; Peng, H.; Grant, P.; Barton, M.D.(2007). Antibiotic and heavy metal resistance in motile aeromonads and Pseudomonads from rainbow trout (Oncorhynchus mykiss) farms in Australia. Int.J.Antimicrob. Agents., 30, 177-182.

Alboghobeysh, H.; Tahmourespour, A.; Doudi, M. (2013). Antibiotic resistance in isolated bacteria from urban sewage and copper smeltery industrial wastewater. Gorgan. J.Uni.Med.Sci.,15(1), 95-102

Alshara, M.(2011). Antimicrobial resistant pattern of Escherichia coli strains isolated from pediatric patients in Jordan. Acta.Med.Iran.,49(5),293-295.

Aluyi, H.S.A.; Daniel, E.O.; Attah, M.U.; Aikhuele, U.E.(2013). Multiple antibiotic resistance among bacteria isolated from hospital environment. The Bioscientist.,1(1),80-85.

Andres, P.; Petroni, A.; Faccone, D.; Pasterán, F.; Melano, R.; Rapoport, M.; Mart 'ýnez, M.; Culasso,C.; Di Bella, A.; Irigoyen, B.; Mulki, J.; Procopio, A.; von Specht, M.; Galas, M. (2005). Extended-spectrum $\beta$-lactamases in Shigella flexneri from Argentina: first report of TOHO-1 outside Japan. Int. J. Antimicrob. Agents., 25, 501-507.

Baquero, F.; Martinez, J.L.; Canton, R.(2008). Antibiotics and antibiotic resistance in water environments. Curr. Opin. Biotechnol.,19, 260-265.

Bauer, A.W.; Kirby, M.M.; Sherris, J.C.; Turck, M.(1966).Antibiotic susceptibility testing by standardized single disc method. AM. J. Clin. Pathol.,45(4), 493- 496.

Cheong, H-T.; Ho, W-Y.; Choo, Q-C.; Chew, C-H.(2014). $\beta$-lactamase gene blaSHV detected in bacteria isolated from retail sushi in Kampar, Malaysia. Biomedical. Res., 25(1), 25-31.

Christina, SH.; Christa, M.; Katrin, SM.; Sabin, M.; Stefanie, S.; Kurin, S.; Johann, B.(2012). Heavy metals in liquid pig manure in light of bacterial antimicrobial resistance. Environ.Res.,113, 21-27.

Cruickshank, R.; Dugiud, J.P.; Marmion, B.P.; Swain, R.H.A. (1975). "Medical Microbiology" 12th.Ed. Churchill living stone, Edinburgh. UK.

Doughari, H.J.; Ndakidemi, P.A.; Human, I.S.; Benade, S.(2011). Virulence factors and antibiotic susceptibility among verotoxic non O157: H7 Escherichia coli isolates obtained from water and wastewater samples in Cape Town, South Africa. African J.Biotech.10(64),14160-14168.

El-Taib, K.A.(2011). Studies on virulence characters of Salmonella typhimurium isolated from animal and human. Rep.Opin.,3(7),37-43.

Eze, E.A.(2012). Systematic variations in drug resistance among some enteric gram-negative bacilli isolated from humans and sewage. J. Microbiol.Antimicrob.,4(1), 6-15.

Fouhy, F.; Paul Ross, R.; Fitzgerald, G.F.; Stanton, C.; Paul, D.; Cotter, P.D.(2014). A degenerate PCRbased strategy as a means of identifying homologues of aminoglycoside and $\beta$-lactam resistance genes in the gut microbiota. BMC Microbiol.,14,25.

Grant, A.J.; Pittard, J. (1974). Incompatibility reactions of R Plasmids isolated from Escherichia coli of animal origin. J. Bacteriol., 120,185-188.

Kamala-Kannan, S.; Lee, K.J. (2008). Metal Tolerance and Antibiotic Resistance of Bacillus species Isolated from Snchon Bay Sediments. South Korea, Biotech.,7(1),149-152.

Karbasidaez, V.; Badami, N.; Emtiazi, G.(2003). Antimicrobial, heavy metal resistance and plasmid profile of coliforms isolated from nosocomial infections in a hospital in Isfahan, Iran. African J. Biotechnol., 2(10),379-383.

Katzung, B.G. (2004). Chemotheraputic Drug. Basic and Clinical Pharmacology. 9th ed: pp. 733-781. 
Khan, M.S.; Zaidi, A.; Wani, PA.; Oves, M.(2009). Role of plant growth promoting rhizobacteria in the remediation of metal contaminated soils .Environ.chem. Lett., 7,1-19.

Licht, TR.; Wilcks, A. (2005). Conjugative Gene Transfer in the Gastrointestinal. Environment. Adv. Appl. Microbiol.,58,77-95.

MacFaddin, J.F.M. (2000). "Biochemical Tests for Identification of Medical Bacteria", $3^{\text {rd }}$ ed., Baltimore: Lippincott Williams and Wilkins.

Manikandan, C.; Amsath, A.(2013). Antimicrobial resistance of enteric pathogens isolated from children with acute diarrhea in Pattukkottai, Tamil Nadu, India. Int. J. Pure Appl. Zool., 1(2), 139-145.

Mgbemena, I.C.; Nnokwe, J.C.; Adjeroh, L.A.; Onyemekara, N.N.(2012). Resistance of Bacteria Isolated from Otamiri River to Heavy Metals and Some Selected Antibiotics. Curr.Res.J.Biol.Sci.,4(5), 551556.

Muhammad, U.K.; Mustafa Alhaji Isa, M.A.; Aliyu, Z.M.(2013). Antimicrobial resistance pattern of pathogenic bacteria isolated from four hospital environment in Sokoto Metropolis, Northwestern, Nigeria. J. Microbiol. Biotech. Res., 3(1),120-124.

Oubrim, N.(2012). Removal of antibiotic-resistant Salmonella in sewage water from wastewater treatment plants in settat and soualem, Morocco. European.J.Sci.Res.,68(4), 565-573.

Pandit, R.J.; Patel, B.; Kunjadia, P.D.; Nagee, A.(2013). Isolation, characterization and molecular identification of heavy metal resistant bacteria from industrial effluents, Amala-khadi- Ankleshwar, Gujarat. Int.J.Environ.Sci., 3(5),1689-1699.

Rachakonda, S.; Cartee, L.(2004). Challenges in antimicrobial drug discovery and the potential of nucleoside antibiotics. Curr. Med. Chem., 11,775-793.

Selim, S.A.; Hagag, N.I. (2013) Analysis of plasmids and Restriction Fragment Length Polymorphisms of Acinetobacter baumannii Isolated from Hospitals - Al Jouf Region - KSA. World Academy of Sci. Engin. and Tech.,78, 152-157.

Sharma, S.; Bhat, GK.; Shenoy, S. (2007). Virulence factors and drug resistance in Escherichia coli isolated from extraintestinal infections. Indian J. Med. Microbiol., 25(4), 369-373.

Tamil Selvi, A.; Anjugam, E.; Archana Devi, R.; Madhan, B.; Kannappan, S.; Chandrasekaran, B. (2012). Isolation and characterization of bacteria from tannery effluent treatment plant and their tolerance to heavy metals and antibiotics. Asian J. Exp. Biol. Sci., 3(1), $34-41$.

Tollefson, L.; Flynn, W.T.; Headrick, M.L.(2008). Regulatory Activities of the U.S. Food and Drug Administration Designed to Control Antimicrobial Resistance in Foodborne Pathogens, in Microbial Food Safety in Animal Agriculture: Current Topics (Eds M.E. Torrence and R.E. Isaacson), Blackwell Publishing, Oxford, UK.

Tulayakul, P.; Boonsoongnern, A.; Kasemsuwan, S.; Wiriyarampa, S.; Pankumnoed, J.; Tippayaluck, S.; Hananantachai, H.; Mingkhwan, R.; Netvichian, R.; Khaodhiar, S.(2011). Comparative study of heavy metal and pathogenic bacterial contamination in sludge and manure in biogas and non-biogas swine farms. J. Environ.Sci., 23(6), 991-997.

Vandepitte, J.; Enbaek, K.; Rohner, P.; Poit, P.; Heuck, C.C. (2003)." Basic Laboratory Procedures in Clinical Bacteriology". World Health Organization, Geneva.

Yismaw, G.; Abay, S.; Asrat, D.; Yifru, S.; Kassu, A. (2010). Bacteriological profile and resistance pattern of clinical isolates from pediatric patients, Gondar University Teaching Hospital, Gondar, and NorthEast Ethiopia. Ethiopian Med. J., 48(4), 293- 300. 